\title{
Knowledge about The Overall Patient's Satisfaction of The Primary Health Care in Saudi Arabia and Common Complains That Brings Patients to The Primary Health Centre
}

\author{
Yousef Ateeg Awad Alsadi ${ }^{1}$, Adnan Meteb Mohamed Almezani ${ }^{1}$, Abdulaziz Ayed M \\ Alshammari ${ }^{1}$, Abdulaziz Ayed Abed Alrashidi ${ }^{1}$, Abdulrahman Saeed Saad Alharbi ${ }^{1}$, Intesar \\ Hadi Eisa Alshammari ${ }^{1}$, Ahmad Hassan A Albargi ${ }^{2}$, Saleh Ali Saleh Kharshan AL Ghamdi ${ }^{3}$ \\ College of Medicine University of Hail ${ }^{1}, \mathrm{KAAU}^{2}$, Rawalpindi Medical College ${ }^{3}$ \\ Corresponding author: Yousef Ateeg Awad Alsadi, E-mail: yousefalsaadi94@gmail.com, Phone no: +966538047705
}

\begin{abstract}
Background: Despite the modern life and the availability of great facilities, patients are not satisfied with the health care offered in the primary health care center in Saudi Arabia. Common complains that bring patients to the primary health care center are usually hypertension, headaches or back pain but there are others that are unknown and common like abdominal pain.

Objectives: This study was done to explore the overall patient's satisfaction of the primary health care in Saudi Arabia and the common complains that bring patients to the primary health centre.

Methods: A cross-sectional study was carried out during the period from January to April 2018 on 864 participants chosen from many different social media platforms to investigate the overall patient's satisfaction of the primary health care in Saudi Arabia and the common complains that bring patients to the primary health centre.

Results: $48.1 \%$ of the participants had visited the primary health care center at a certain point of time, $33.6 \%$ of the participants went to the primary health center first before going to the hospital, $43.7 \%$ of the participants received a professional health care whenever they enrolled to the primary health care centers, $51.9 \%$ of the participants usually found the prescribed medications at the primary health care center and $30 \%$ of the participants claimed abdominal when they visited the primary health care center. Regarding patient's satisfaction, $18.8 \%$ of the participants rate the primary health care center 5 out of 10. Finally, $90.6 \%$ of the participants thought that the ministry of health should pay more attentions to the primary health care centers.

Conclusion: overall patient's satisfaction about the primary health care center in Saudi Arabia was as great as we could expect. The main complain that brings participants to the primary health care centers was abdominal pain.
\end{abstract}

Keywords: satisfaction, centre, abdominal pain.

\section{INTRODUCTION}

Time is an important factor in primary healthcare since it is associated with improving health outcomes and contributing to cost control ${ }^{(1,2)}$. Availability and accessibility are essential characteristics of efficient and effective primary healthcare systems ${ }^{(3,4,5)}$. The use of ambulatory primary healthcare services for multiple reasons, including but not limited to routine care, mental health, child and maternity care, liaison with home care, health promotion and disease prevention, end of life care and having timely access to primary care has been shown to increase patient satisfaction as well as the quality of care provided in countries like Canada (5). However, recent studies have shown that access to family physicians is becoming difficult due to physician shortages and increasing rates of disability and chronic disease ${ }^{(5)}$. There are many issues in the primary health care center like the time that is spent waiting for a primary healthcare appointment can often lead to a physical and emotional stress on the patient who is in pain or worried about a serious health condition ${ }^{(6)}$. Recent studies have shown that adverse consequences maybe established from prolonged waiting for primary health care appointments ${ }^{(7,8)}$. For example, prolonged waiting times for serious conditions like heart disease and cancer have been associated with an increased risk of morbidity and mortality due to a delay in care ${ }^{(9,10,11)}$. Furthermore, patients who are suffering from mental health issues and who do not receive a professional care, often experience a rapid decline in their health condition and a lost opportunity for effective and efficient treatment ${ }^{(7)}$. Patients satisfaction with the health care is a basic component in evaluating health care quality (12). The importance of the patient's opinion and his 
perception of treatment and care at health facilities are now well known in all developed systems of health care ${ }^{(13)}$. Patients who are usually coming to the primary health care center are those who are either diabetic or hypertensive (14). Complains of back pain, abdominal pain, chest pain, headache and chronic cough are increasing these days among patients who visit a primary health care center seeking for help ${ }^{(14)}$.

\section{MATERIALS AND METHODS}

A cross-sectional study involving 864 participants all over Saudi Arabia was done between January to April 2018. The sample size for this study was selected and distributed randomly. A self-administered questionnaire was developed after a careful review of literature on the subject and it included 10 questions distributed to people in Saudi Arabia. The questionnaire had two parts. Part one; demographical data that includes age, gender and marital status. Part two; the participants were asked whether they have visited a primary health care center or not, whether they go first to the primary health care center before going to the hospital when they feel sick or not, whether they receive the professional and absolute care whenever they visit a primary health care center or not. Participants were also asked if they always get the prescribed medications from the primary health care or not, what was their complain when they visited the primary health care center, what is their overall rate satisfaction to the primary health care center and should the ministry of health pay more attention to the primary health care center or not. Data were collected through a survey that was distributed through a websitelink through participants in Saudi Arabia in different social media sites and platforms. Statistics were descriptively used to describe the answers of the participants in the study using numbers and percentages.

The answers were compared to different questions within the different groups using Pearson chi-square test. Statistical significance was set at $p<0.05$ and analysis was performed using IBM SPSS statistics, version 23 (IBM, Armonk, NY, USA).

\section{The study was done after approval of ethical board of University of Hail.}

\section{RESULTS}

A total of 864 participant women from all over Saudi Arabia were participated in the study and $44.9 \%$ of them were between the ages of 20 to 30 years old, $24.1 \%$ were between 30 to 40 years old, $21 \%$ were between 10 to 20 years old and only $9.3 \%$ were more than 40 years old (Table1). More than half of the participants $57.6 \%$ were single and $42.4 \%$ were married (Table 2). Regarding participants who have visited the primary health care center at a certain point of time, $48.1 \% \%$ of the participants did (Table 3). $33.6 \%$ of the participants usually go to the primary health center first before going to the hospital and $43.8 \%$ of the participants claim that they receive a professional and absolute care whenever they go to the primary health care center (Table 4). 51.9\% of the participants said that they usually find the prescribed medications at the health care center (Table 5). $30 \%$ of the participants claimed that their main complain whenever they visited a primary health care center was abdominal pain (Table 6). $18.8 \%$ of the participants gave the overall rate to the primary care center 5 out of 10 (Table 7). $90.6 \%$ of the participants thought that the ministry of health should pay more attentions to the primary health care centers (Table 8).

Table (1): Age distribution of the participants

\begin{tabular}{|l|l|l|}
\hline Age & Frequency & Percent \\
\hline $1-10$ & 7 & 0.7 \\
\hline $10-20$ & 181 & 21 \\
\hline $20-30$ & 388 & 44.9 \\
\hline $30-40$ & 208 & 24.1 \\
\hline$>40$ & 80 & 9.3 \\
\hline Total & 864 & 100 \\
\hline
\end{tabular}


Knowledge about The Overall Patient's Satisfaction of The Primary Health Care in Saudi Arabia...

Table (2): Marital status and gender of the participants:

\begin{tabular}{|l|l|l|}
\hline $\begin{array}{l}\text { Marital } \\
\text { status }\end{array}$ & Frequency & Percent \\
\hline Single & 498 & 57.6 \\
\hline Married & 366 & 42.4 \\
\hline Total & 864 & 100 \\
\hline Gender & & \\
\hline Male & 585 & 67.7 \\
\hline Female & 279 & 32.3 \\
\hline Total & 864 & 100 \\
\hline
\end{tabular}

Table (3): Participants visited the primary health care center at a certain point of time:

\begin{tabular}{|l|l|l|}
\hline $\begin{array}{l}\text { Visited the primary health care } \\
\text { center at a certain point of time }\end{array}$ & Frequency & Percent \\
\hline Yes & 416 & 48.1 \\
\hline No & 448 & 51.9 \\
\hline Total & 864 & 100 \\
\hline
\end{tabular}

Table (4): Participants went to the primary health center first before going to the hospital and received a professional health care:

\begin{tabular}{|l|l|l|}
\hline $\begin{array}{l}\text { Go to the primary health center } \\
\text { first before going to the hospital }\end{array}$ & Frequency & Percent \\
\hline Yes & 290 & 33.6 \\
\hline No & 574 & 66.4 \\
\hline Total & 864 & 100 \\
& \\
\hline Receive a professional health care \\
\hline Yes & 378 & 43.7 \\
\hline No & 486 & 56.3 \\
\hline Total & 864 & 100 \\
\hline
\end{tabular}

Table (5): Availability of the prescribed medications at the health care center:

\begin{tabular}{|l|l|l|}
\hline $\begin{array}{l}\text { Find the prescribed medications } \\
\text { at the health care center }\end{array}$ & Frequency & Percent \\
\hline Yes & 448 & 51.9 \\
\hline No & 416 & 48.1 \\
\hline Total & 864 & 100 \\
\hline
\end{tabular}

Table (6): Main complain of visiting the primary health care center:

\begin{tabular}{|l|l|l|}
\hline $\begin{array}{l}\text { Main complain of visiting the } \\
\text { primary health care center }\end{array}$ & & \\
\hline Abdominal pain & 259 & 30 \\
\hline Chronic cough & 243 & 28.1 \\
\hline Chest pain & 212 & 24.5 \\
\hline Headache & 212 & 24.5 \\
\hline Back pain & 128 & 14.8 \\
\hline Hypertension & 79 & 9.1 \\
\hline Diabetes & 59 & 6.8 \\
\hline
\end{tabular}

Table (7): Overall rate to the primary care center out of 10 : 


\begin{tabular}{|l|l|l|}
\hline $\begin{array}{l}\text { Overall rate to the primary care } \\
\text { center out of } 10\end{array}$ & Frequency & Percent \\
\hline 1 & 94 & 10.9 \\
\hline 2 & 24 & 2.8 \\
\hline 3 & 71 & 8.2 \\
\hline 4 & 81 & 9.4 \\
\hline 5 & 162 & 18.8 \\
\hline 6 & 107 & 12.4 \\
\hline 7 & 121 & 14 \\
\hline 8 & 120 & 13.9 \\
\hline 9 & 22 & 2.5 \\
\hline 10 & 62 & 7.2 \\
\hline Total & 864 & 100 \\
\hline
\end{tabular}

Table (8): Role of Ministry of Health in giving great attentions to the primary health care centers.

\begin{tabular}{|l|l|l|}
\hline $\begin{array}{l}\text { Ministry of health should pay } \\
\text { more attentions to the primary } \\
\text { health care centers }\end{array}$ & Frequency & Percent \\
\hline Yes & 783 & 90.6 \\
\hline No & 81 & 9.4 \\
\hline Total & 864 & 100 \\
\hline
\end{tabular}

\section{DISCUSSION}

In the present study, we found that there were an increased number of people who are not satisfied with the services provided by the primary heath care center in Saudi Arabia. Patient satisfaction is considered an important component when measuring health outcomes and quality of care that was provided to the patients when they visit the primary health care center seeking for help ${ }^{(15,16)}$.

This relationship is very complicated between patients perceived expectations and needs from the health services provided to them when they are in their earnest and serious need for medical help ${ }^{(17)}$. So, patient's overall satisfaction of the service provided to them is one of the variables affecting the outcomes of health care and use of services. In order to improve the quality of care, all unprofessional services and help that the patients are facing whenever they visit a primary health care center must be eliminated $(18,19)$.

A previous study has shown that patients with higher satisfaction have higher trust in their doctors, are more prone to follow and do as doctors' advice and are more responsible for their own health care ${ }^{(20)}$. Therefore, improving the satisfaction of the patients will actively promote health communication. Health communication, on the other hand, aims at improving the public health care, which is another way with which satisfaction positively affects universal health. Health workers play an essential role in both of these processes. Fifth China National Health Services Survey showed that doctor and patient relationships are gradually improving in China which reflects the patient's outcome and satisfaction. Therefore, the role of the health workers' in popularizing health knowledge should be more professional and focus on relationships with the patients $\left({ }^{21)}\right.$. Regarding the common complain that usually bring patients to the primary health care center, $30 \%$ of the participants said that abdominal pain is their main complain.

\section{CONCLUSION}

We can conclude that the overall patient's satisfaction of the primary health care center in Saudi Arabia is really not pleasant considering the availabilities of facilities and good doctors working in the kingdom. Ministry of health should pay more attention to the primary health care centers since they are the first place that the patient usually visits whenever he feels sick. Doctors should educate people about dealing with common symptoms like abdominal pain and when to know that is necessarily to visit a doctor.

\section{REFRENCES}

1. The College of Family Physicians of Canada (2015): The Wait Starts Here. 
Available

at:

https://www.cfpc.ca/uploadedFiles/Resour ces/Resource_Items/ENGLISH2OPCWTP2 OFINAL20-20DECEMBER202009.pdf

2. Comino EJ, Davies GP, Krastev Y et al. (2012): A systematic review of interventions to enhance access to best practice primary health care for chronic disease management, prevention and episodic care. BMC Health Serv Res., 12:415.

3. Fournier J, Heale R, Rietze LL (2012): I can't wait: advanced access decreases wait times in primary healthcare. Healthc Q., 15(1):64-8.

4. World Health Organization (2015): Modeling Physical Accessibility to Health Care and Geographic Coverage. Available at: http://www.who.int

5. College of Family Physicians of Canada (2015): Family Medicine in Canada: Vision for the Future. Available at: http://www.cfpc.ca/uploadedFiles/Resourc es/Resource_Items/FAMILY_MEDICINE_ IN_CANADA_English.pdf

6. College of Family Physicians of Canada (2015): Improving Access to Care for Patients in Canada. A vailable at: http://www.cfpc.ca/uploadedFiles/Resourc es/Resource_Items/CFPC20Position20Stat ement-20ENG20.pdf

7. Pomera Pomerantz A, Cole BH, Watts BV et al. (2008): Improving efficiency and access to mental health care: combining integrated care and advanced access. Gen Hosp Psychiatry,30(6):546-51.

8. The Center for Spatial Economics (2015): The Economic Cost of Wait Times in Canada. Available at: http://www.cimca.ca/i/m/TheCentreForSp atialEconomics-Jun06.pdf

9. Barua B, Esmail N, Jackson T (2015): The Effect of Wait Times on Mortality in Canada. Available at: https://www.fraserinstitute.org/sites/defaul t/files/effect-of-wait-times-on-mortality-incanada.pdf

10. Starfield B, Shi L, Grover A et al. (2005): The effects of specialist supply on populations' health: assessing the evidence

https://www.ncbi.nlm.nih.gov/pubmed/15 769797

11. Fahmy N, Aprikian A, AlOtaibi $M$ et al .(2009): Impact of treatment delay in patients with bladder cancer managed with partial cystectomy in Quebec: a populationbased study. Can Urol Assoc J., 3(2):1315.

12. Miro S, Bui A, Rodriguez M (1997): he perceived quality of hospital care. Gac Sanit., 11(4): 89-176.

13. Abdal K, Aday, Walker G (1996): patient satisfaction in government health facilities in the state Qater. J Community Health, 21(5): 58-349.

14. WHO: The global burden of disease (2004): Available at: http://www.who.int

15. Donabedian A (1966): Evaluating the quality of medical care. Milbank Mem Fund., 44(1): 166-206.

16. Ware D, Davies A, Stewart T (1978): the measurement and meaning of patient satisfaction. Health Med. Serv. Rev., 1(1): 3-15.

17. Sara N Bleich, Emre Ozaltin, Christopher JL Murray (2009): How does satisfactions with the health care system relate to patient experience. WHO Study. Available at: http://www.who.int/bulletin/volumes/87/4/ 07-050401/en/

18. Tong, Chung, Wong D (1997): Predictive factor in global and anesthesia satisfaction in ambulatory surgical patients. Anesthesiology, 87(4): 64-856.

19. Larrabee, Ferri, Hartig M (1997): Patient satisfaction on with nurse practitioner in primary Care. Abailable at: http://europepmc.org/abstract/med/921254 2

20. Hulka BS, Cassel JC, Kupper LL et al .(1976): Communication, compliance, and concordance between physicians and patients with prescribed medications. Am J Public Health, 66(9):847-53.

21. Xu Lin (2014): One of the fifth national health services survey - resident's satisfaction. Chinese J Health Inf Manag., (2):104-5. 